\title{
Mediastinal tumours and pseudo-tumours: a comprehensive review with emphasis on multidisciplinary approach
}

\author{
Maria-Rosa Ghigna (i) and Vincent Thomas de Montpreville
}

\author{
Number 8 in the Series "Thoracic oncology" \\ Edited by Rudolf Huber and Peter Dorfmüller
}

Dept of Pathology, Marie Lannelongue Hospital, Le Plessis Robinson, France.

Corresponding author: Vincent Thomas de Montpreville (v.thomasdemontpreville@hml.fr)

Shareable abstract (@ERSpublications)

Given the mediastinal anatomical heterogeneity, the correct positioning of mediastinal lesions becomes primal, in order to first establish a clinical suspicion and then to assist in planning biopsy and surgical procedure https://bit.ly/3p0gsk3

Cite this article as: Ghigna M-R, Thomas de Montpreville V. Mediastinal tumours and pseudo-tumours: a comprehensive review with emphasis on multidisciplinary approach. Eur Respir Rev 2021; 30: 200309 [DOI: 10.1183/16000617.0309-2020].

Copyright @The authors 2021

This version is distributed under the terms of the Creative Commons Attribution Non-Commercial Licence 4.0. For commercial reproduction rights and permissions contact permissions@ersnet.org

Received: 23 Sept 2020 Accepted: 8 Jan 2021

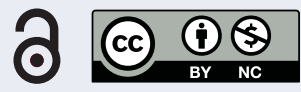

\section{Abstract}

The diagnosis of a mediastinal mass may be challenging for clinicians, since lesions arising within the mediastinum include a variety of disease entities, frequently requiring a multidisciplinary approach. Age and sex represent important information, which need to be integrated with imaging and laboratory findings. In addition, the location of the mediastinal lesion is fundamental; indeed, we propose to illustrate mediastinal diseases based on the compartment of origin. We consider that this structured approach may serve as hint to the diagnostic modalities and management of mediastinal diseases. In this review, we present primary mediastinal tumours in the evolving context of new diagnostic and therapeutic tools, with recently described entities, based on our own experience with $>900$ cases encountered in the past 10 years.

\section{Introduction}

Mediastinal masses are rather uncommon, but nevertheless include several entities, presenting with a large variety of clinical and pathological features. A standardised approach to patients presenting a mediastinal mass does not appear appropriate, considering their heterogeneity. Combining clinical data, age, sex and imaging represents the first step in the diagnostic proceedings, leading to a presumptive diagnosis in most patients. In the present review we expose the key features of anterior, middle and posterior mediastinal masses, providing the experience we have accumulated in the investigation and treatment of mediastinal masses in our tertiary referring institution (table 1).

Mediastinum is a segment of the thorax containing vital structures such as heart, great vessels, trachea, main bronchi, oesophagus, thymus and lymphatic and nerve structures. Given this anatomical heterogeneity, the correct positioning of mediastinal lesions becomes primal, in order to first establish a clinical suspicion and then to assist in planning biopsy and surgical procedure. Several compartment schemes based on lateral chest radiography have been used until very recently. However, as the diagnostic examination of patients, biopsy planning and surgical treatment are scheduled on computed tomography (CT) findings, attention has focused on more recent classification systems, based on CT cross-section imaging. First, the model elaborated by the Japanese Association for Research on the Thymus (JART) in order to ease the localisation of mediastinal masses identifies four mediastinal compartments [1]. The International Thymic Malignancy Interest Group (ITMIG) also proposed a classification system, based on a modified JART model, dividing the mediastinum into three compartments [2]. 
TABLE 1 Frequencies of sex and age of 942 consecutive primary tumours and cysts of the mediastinum encountered in a 10-year period (2010-2019) at Marie Lannelongue Hospital (Le Plessis Robinson, France)

\begin{tabular}{|c|c|c|c|c|c|c|}
\hline & \multirow[t]{2}{*}{ Cases } & \multicolumn{2}{|c|}{ Sex } & \multicolumn{2}{|c|}{ Age years } & \multirow[t]{2}{*}{ Total } \\
\hline & & $\mathrm{F}$ & M & Range & Mean & \\
\hline Thymic lesions & & & & & & $507(53.8)$ \\
\hline Congenital cyst & $44(8.55)$ & 20 & 24 & $27-81$ & 64.10 & \\
\hline Multilocular cyst & $7(1.39)$ & 4 & 3 & $31-62$ & 29.61 & \\
\hline Cholesteroloma & $3(0.59)$ & 0 & 3 & $25-53$ & 35.07 & \\
\hline Myasthenia gravis & $138(27.4)$ & 92 & 46 & $8-69$ & 31.19 & \\
\hline Hyperplasia without myasthenia gravis & $36(7.16)$ & 20 & 16 & $8-79$ & 35.82 & \\
\hline Thymolipoma & $2(0.4)$ & 1 & 1 & $20-61$ & 40.86 & \\
\hline Thymomas & $239(47.5)$ & 121 & 111 & $9-90$ & 58.43 & \\
\hline Thymic carcinomas & $27(5.37)$ & 12 & 15 & $14-82$ & 52.46 & \\
\hline Carcinoid tumours & $11(2.19)$ & 2 & 9 & $28-72$ & 53.33 & \\
\hline Nonthymic cysts & & & & & & $61(6.5)$ \\
\hline Bronchogenic & $20(32.8)$ & 12 & 8 & $7-64$ & 41.42 & \\
\hline Pleuro-pericardial & $38(62.3)$ & 19 & 19 & $9-74$ & 52.25 & \\
\hline Müllerian & $3(9.84)$ & 3 & 0 & $47-57$ & 52.09 & \\
\hline Lymphomas & & 104 & 110 & $14-84$ & 41.20 & $214(22.7)$ \\
\hline Diffuse large B-cell & $81(37.9)$ & 42 & 39 & $15-84$ & 44.49 & \\
\hline Hodgkin lymphoma & $110(51.4)$ & 55 & 55 & $14-77$ & 36.72 & \\
\hline T-lymphoblastic & $10(4.67)$ & 2 & 8 & $18-63$ & 45.60 & \\
\hline Miscellaneous & $13(6.07)$ & 5 & 8 & $25-83$ & 58.06 & \\
\hline Germinal cell tumours & & 16 & 55 & $0-74$ & 30.73 & $71(7.5)$ \\
\hline Teratoma & $25(35.2)$ & 14 & 11 & $0-74$ & 28.16 & \\
\hline Malignant nonseminomatous & $37(52.1)$ & 2 & 35 & $15-65$ & 31.96 & \\
\hline Seminoma & $9(12.7)$ & 0 & 9 & $20-48$ & 32.80 & \\
\hline Benign connective tumours & & & & & & $63(6.7)$ \\
\hline Castleman disease & $4(6.35)$ & 2 & 2 & $30-77$ & 45.65 & \\
\hline Lipoma & $4(6.35)$ & 2 & 2 & $55-61$ & 59.50 & \\
\hline Angioma & $10(15.9)$ & 3 & 7 & $0-74$ & 47.89 & \\
\hline Schwannoma & $25(39.7)$ & 16 & 9 & $10-78$ & 46.72 & \\
\hline Neurofibroma & $5(7.94)$ & 2 & 3 & $42-56$ & 44.37 & \\
\hline Ganglioneuroma & $6(9.52)$ & 4 & 2 & $6-60$ & 30.03 & \\
\hline Paraganglioma & $9(14.3)$ & 6 & 3 & $15-78$ & 53.25 & \\
\hline Miscellaneous malignancies & & & & & & $26(2.8)$ \\
\hline Sarcomas & $21(80.8)$ & 12 & 9 & $6-79$ & 43.03 & \\
\hline Undifferentiated malignant tumours & $5(19.2)$ & 3 & 2 & $18-48$ & 41.30 & \\
\hline
\end{tabular}

Data are presented as $\mathrm{n}(\%)$ or $\mathrm{n}$, unless otherwise stated. F: female; M: male. Bold type represents significant features.

One of the main differences between these classifications based on CT cross-section imaging implies the number of mediastinal compartments. The JART model distinguishes superior, anterior, middle and posterior divisions, allowing accurate identification of lesions arising from the upper part of the mediastinum. Despite the accuracy tied to this system, potential disadvantages may result from the artificial and nonanatomical separation of the superior and inferior mediastinum, which may complicate the general application of this model. The ITMIG three-compartment system identifies an anterior, middle and posterior compartment, delimited by boundaries assessed along anatomic planes. The only inconvenience of this model may result from the inadequate disjunction of lesions arising in the upper mediastinum, such as thyroid goitre. The aforementioned classification systems are very helpful to localise and therefore to identify the site of origin of a mediastinal lesion. However, some mediastinal masses may be very large, extending from one division to another. One method commonly used by thoracic radiologists is the so-called "centre method", where the identification of the centre of the lesion on axial CT images defines theoretically the site of origin. In addition, the evaluation of the degree of displacement of mediastinal structures may help to identify the origin site.

The general utilisation of a standardised system of lesions topographical identification is of great help in diagnosis and treatment of mediastinal diseases, facilitating the interactions among health professionals of different disciplines. 
Special considerations on biopsy sampling and histological analysis of mediastinal lesions The histological analysis of biopsy and surgical specimen is fundamental to assess and/or to confirm clinical diagnosis, providing essential prognostic and predictive information in specific fields of thoracic pathology. Histological examination includes sequential stages based on the morphological analysis, which drives the selection of tissue markers to be tested. The immunophenotyping contributes to solve many "pathological issues" such as the histogenesis of morphologically poorly differentiated neoplasms, the precise characterisation of lesions (especially in haematopathology), the identification of the primary site of origin of neoplasms and the research for predictive/prognostic factors in selected diseases. The phenotype of mediastinal lesions is performed on biopsy or surgical specimens in the current pathology practice.

The biopsy of mediastinal lesions is accurately pondered in multidisciplinary consensus meetings, where, on the basis of clinical and imaging features, some entities may be directly surgically resected bypassing superfluous extra stages. For example, thyroid goitres, mature teratoma or thymoma display pathognomonic features and are commonly not biopsied. In contrast, in cases of clinical suspicion of lymphoma, it is mandatory to quickly obtain tissue rather than to pursue additional imaging as treatment cannot be planned on clinical grounds. Diverse techniques are available to retrieve lesional tissue, including CT-guided transthoracic needle biopsy, mediastinotomy, open surgical biopsy or video-assisted thoracoscopic biopsy. The selection of the biopsy technique is influenced by patient comorbidities, as well as lesion size and location. Moreover, especially in the field of haematopathology, the tumour phenotyping requires an adequate amount of tissue, making a more invasive technique more suitable than needle biopsy or cytology.

\section{Anterior mediastinum (pre-vascular compartment)}

Most mediastinal tumours display a predilection for one mediastinal compartment over the others; as a consequence, the correct identification of the site of origin is central to assess a clinical diagnosis.

Based on the ITMIG landmarks of mediastinal compartments, the most common lesions found in the pre-vascular segment include thymic diseases (hyperplasia and tumours), germ cell tumours, lymphoma, metastatic adenopathy and intrathoracic goitre. Data about the real incidence of the anterior mediastinal mass may vary from series to another, for reasons tied to the variability of the radiological classification systems adopted to identify the mediastinal compartment or the inclusion/or exclusion of non-neoplastic processes [3] (thymic or pericardial cysts). Despite these limitations, several studies have reported the following figures: 35\% thymic tumours, 25\% lymphomas (Hodgkin lymphoma 13\%, non-Hodgkin lymphoma $12 \%$ ), endocrine tumours $\sim 15 \%$, germ-cell tumours $20 \%$ (10\% benign teratoma, $10 \%$ malignant germ-cell tumours) and 5\% thymic benign lesions [4]. The majority of tumours arising within the anterior mediastinum are epithelial, with thymomas accounting for the most frequent tumour type in the adult population. Thymic tumours are mostly malignant, including different pathological subtypes, which are classified according to the current World Health Organization (WHO) classification of mediastinal tumours [5, 6]. The data collection (from 2000 to 2019) indicates the Masaoka-Koga stage and frequency of myasthenia gravis according to the histological thymoma subtypes (table 2). True thymic hyperplasia and thymic hyperplasia with lymphoid follicles are benign tumour-like conditions that need accurate distinction from other neoplasms within this thymic compartment [7]. While the former is

TABLE 2 Frequency of myasthenia gravis and Masaoka-Koga stages according to histological types of thymomas in a series of 239 cases encountered in a 10-year period (2010-2019) at Marie Lannelongue Hospital (Le Plessis Robinson, France)

\begin{tabular}{|c|c|c|c|c|}
\hline \multirow{2}{*}{ 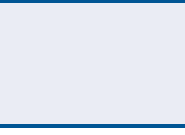 } & \multirow{2}{*}{ Cases } & \multirow[t]{2}{*}{ Myasthenia gravis } & \multicolumn{2}{|c|}{ Masaoka-Koga } \\
\hline & & & $I / I I$ & III/IV \\
\hline A & $24(10)$ & $1(4.2)$ & $18(75)$ & $6(25)$ \\
\hline$A B$ & $62(25.9)$ & $7(11)$ & $52(83.9)$ & $10(16.1)$ \\
\hline Micronodular & $5(2.09)$ & $0(0)$ & $4(80)$ & $1(20)$ \\
\hline B1 & $36(15.1)$ & $15(42)$ & $20(58.8)$ & $14(41.2)$ \\
\hline B2 & $69(28.9)$ & $37(54)$ & $40(59.7)$ & $27(40.3)$ \\
\hline B3 & $40(16.7)$ & $22(55)$ & $10(25.6)$ & $29(74.4)$ \\
\hline Unclassified & $3(1.26)$ & $1(33)$ & $1(100)$ & $0(0)$ \\
\hline Total & $239(100)$ & $83(35)$ & $145(62.5)$ & $87(37.5)$ \\
\hline
\end{tabular}


characterised by an enlarged thymus with a preserved thymic pattern, frequently occurring after other primary conditions or medical treatment (such as chemotherapy, corticosteroids, etc.), the latter is the result of the growth of lymphoid follicles within thymic tissue [7]. Thymic hyperplasia with lymphoid follicles is also associated with autoimmunity (myasthenia gravis) [8]. Other benign diseases include thymic cysts, which may be congenital, developing from remnants of the nasopharyngeal duct or acquired as a consequence of long-lasting inflammatory diseases. Data on clinical presentation, classification, histology and prognosis of thymic tumours are presented in a dedicated review within this series [9]; therefore, we focus on mediastinal lymphoma and germ-cell tumours, which represent an important proportion of anterior mediastinal tumours.

The mediastinum represents the most common site of origin of extragonadal germ-cell tumours. These neoplasms, encompassing different pathological types, account for $20 \%$ of anterior mediastinal tumours [10]. However, their pathogenesis remains still unclear. Two main theories have been proposed to explain the pathogenesis of this intriguing group of neoplasms. Based on the observation that most germ-cell tumours develop within the thymic parenchyma, one theory suggests that they may originate from pluripotent cells migrating into the mediastinum with thymic anlage during embryogenesis. Although attractive, this theory cannot clarify the occurrence of germ-cell tumours in other extragonadal sites (such as retroperitoneum, sacrococcygeal area, pineal region). An additional theory has been elaborated on the fact that most extragonadal germ-cell tumours are located along the body midline; it has been suggested that some embryonic cells could be misplaced during embryo development, potentially giving rise to neoplasms [11].

\section{Mediastinal germ-cell tumours}

Mediastinal germ-cell tumours share the same histological features with their gonadal counterpart. The clinical suspicion of germ cell tumour is supported by demographic information (age $<40$ years, sex), clinical presentation (absence of myasthenia gravis, lack of lymphoma "B" symptoms (see later) and occurrence of gynaecomastia, for example), laboratory tests (tumour markers such as $\alpha$-fetoprotein, $\beta$-human chorionic gonadotrophin (HCG)) and imaging features (heterogeneous anterior mediastinal mass containing fat tissue or bone). The indication to perform core or surgical biopsy must be thoroughly discussed in multidisciplinary consensus meetings and may be considered when the clinical and radiological suspicion of thymoma is retained highly improbable. Among mediastinal germ-cell tumours, teratoma is the most frequent histological type, accounting for $50 \%$ of mediastinal germ-cell tumours [12]. They especially occur in young patients, although sporadic cases have been reported at any age. Teratomas are equally diagnosed in both sexes, clinically presenting with symptoms related to the compression or displacement of mediastinal structures. On CT scans, teratomas can be confidently identified, based on heterogeneous appearance (cyst, presence of fat and bone tissue, calcifications). From a histological point of view, teratomas are neoplasms composed of several tissues, derived from the three embryonic layers, and are usually made of morphologically mature tissues. On gross examination, these neoplasms are frequently cystic and well delimited, filled with hair frequently intermingled with a yellow-brown sebaceous material. On histological examination, mature teratomas are constituted by several tissues such as epidermis, intestinal, bronchial, pancreatic tissue, nervous tissue, bone and cartilage, thyroid, smooth muscle and different components derived from the three germinal layers. Malignant transformation of one or more mature tissues has been rarely documented in mediastinal teratoma. Mature teratomas are well-circumscribed masses that do not invade adjacent mediastinal structures. A small proportion of teratomas exhibit immature histological features and appear as large and variegated masses on gross examination. Haemorrhage and necrosis are frequently found and upon histological analysis they display a mixture of embryologically different tissues, among which immature nervous tissue is predominant. Immature teratomas represent $<1 \%$ of mediastinal teratomas and are more frequently diagnosed in children. Immature teratomas behave as malignant tumours in late teens and adulthood; prognosis is clearly better when occurring in children $[13,14]$.

\section{Seminoma}

Pure seminoma accounts for up to $35 \%$ of mediastinal germ-cell tumours and occurs exclusively in male patients in their third and fourth decades of life [15]. On CT scans these neoplasms appear as homogeneous masses and are frequently associated with pulmonary metastasis. Serum $\beta$-HCG may be slightly elevated, while lactate dehydrogenase (LDH) is usually augmented. Core needle biopsy or surgical biopsy is sufficient to assess diagnosis and may be considered when laboratory tests support the clinical suspicion. On gross section, seminomas appear as large lobulated well-circumscribed masses, usually infiltrating adjacent structures. On histological examination, the neoplastic population is composed of large cells with clear cytoplasm containing a centrally located nucleus with prominent nucleoli [16]. The stroma contains a dense lymphoid population and occasionally granulomas. Isolated large multinucleate cells 
reminiscent of syncytiotrophoblasts may be observed. Mediastinal seminomas are germ-cell tumours with good prognosis, currently treated by chemotherapy only [17].

\section{Primary malignant nonseminomatous germ-cell tumours}

Primary malignant nonseminomatous germ-cell tumours developing in the mediastinum are a subset of tumours generally carrying a poor prognosis, occurring between the ages of 20 and 39 years with an important male predominance [18]. Patients present with anterior mediastinal mass and elevation of serum $\beta$-HCG $>1000 \mathrm{U} \cdot \mathrm{L}^{-1}$ and/or elevation of serum $\alpha$-fetoprotein. On imaging CT scans, these neoplasms appear as large and heterogeneous masses, displacing mediastinal structures, frequently associated with lung nodules. The sum of imaging and laboratory findings are sufficient to confirm diagnosis, without the need for biopsy. However, patients with negative tumour markers or slight elevation of $\beta$-HCG require biopsy to assess the diagnosis. On histological examination, extragonadal nonseminomatous germ-cell tumours display the same components as their gonadal counterparts. Various combinations of embryonal carcinoma, yolk sac and choriocarcinoma can be promptly identified. Moreover, the development of a sarcomatous component has been described in mediastinal germ-cell tumours, with rhabdomyosarcoma and angiosarcoma being most commonly found. Special considerations pertain to the prognosis of extragonadal germ-cell tumours primarily arising in the mediastinum. In contrast to mediastinal seminoma, which is sensitive to radiotherapy and chemotherapy, mediastinal nonseminomatous germ-cell tumours respond poorly to chemotherapy, with $40-50 \%$ overall survival [11]. Metastatic disease at diagnostic assessment further worsened the prognosis, with only $25 \%$ survival [19]. The surgical resection of the tumour mass is usually considered after chemotherapy in order to evaluate the degree of response, to remove resistant tumours and eventually readjust the treatment [20].

\section{Lymphomas}

Lymphomas are the second most diagnosed group of tumours arising in the anterior mediastinum following thymic disease, according to several studies [21-23]. The classical phenotype is that of a young male/female (most commonly aged 10-40 years), clinically asymptomatic or presenting with mild-to-moderate respiratory symptoms and/or B symptoms (fever, drenching night sweats, loss of body weight). On imaging, many mediastinal lymphomas appear as a mass arising within the thymus rather than nodes. Laboratory tests may identify elevation of $\mathrm{LDH}$, bone marrow involvement or neoplastic cells in pleural effusion. The diagnosis of mediastinal lymphoma can be confidently suspected on the basis of clinical and imaging findings; however, tissue analysis is needed to confirm diagnosis and to fully identify the histological subtype, in order to set up the treatment [24]. When considering histology, Hodgkin lymphoma is the most common diagnosed subtype. Indeed, it is the predominant lymphoma found in young females, forming large anterior mediastinal masses. It may be asymptomatic and discovered incidentally at thoracic radiography, or it may be revealed by cough and sometimes dyspnoea (secondary to bronchial compression and irritation), fever, itching and night sweats. Very few patients present with a more severe clinical picture secondary to large venous trunks compression leading to superior vena cava syndrome. On imaging, Hodgkin lymphomas appear as solid and lobulated lesions without calcifications. Hodgkin lymphomas may be very large, infiltrating into adjacent tissues (lung, nerves, vessels); lesions are firm and lobulated, with some foci of necrosis. The histological variant more commonly diagnosed in mediastinum is the scleronodular variant, whose hallmark is a nodular appearance at low magnification and a huge sclerotic pattern. In addition, neoplastic cells may be scant to the point of being overwhelmed by the reactive inflammatory cell population and fibrosis [25]. The sum of these histological features frequently makes the diagnosis very challenging on core needle biopsy [26]. The detection and phenotypic characterisation of Reed-Sternberg cells are the basis of histological classification and are more likely to be achieved on open surgical biopsy or video-assisted thoracoscopic surgery than by needle core specimen [27]. Combining radiotherapy and chemotherapy, patients achieve a good survival rate, with 95\% of patients alive at 10 years, even in advanced disease [28, 29].

\section{Non-Hodgkin lymphomas}

Non-Hodgkin lymphomas affecting the mediastinum are represented by diffuse large B-cell lymphoma and lymphoblastic lymphoma. Among diffuse large B-cell lymphomas, primary mediastinal B-cell lymphoma presents distinctive clinical, demographical and biological phenotype compared to other subtypes of diffuse large B-cell lymphoma [21, 30]. More precisely, this entity accounts for $\sim 10 \%$ of all diffuse large-cell lymphomas, affecting adolescents and young adults, with a female predominance [25, 31]. The clinical presentation may be that of superior vena cava syndrome in half of cases, owing to the rapid growth of the mass and infiltration into mediastinal structures. Pleural/pericardial effusion has been reported in approximately $30-50 \%$ of cases [31, 32]. Extrathoracic disease, with enlargement of lymph nodes outside the mediastinum and bone marrow involvement, is rarely found. Systemic symptoms such as fever and weight loss are rarely described, affecting $<20 \%$ of patients. Primary mediastinal large B-cell lymphoma 
arises within the thymus, originating from the thymic B-cell [33, 34]. On histological examination, the tumour growth is characterised by diffuse proliferation of large and/or medium-sized cells, containing pale cytoplasm and irregular shaped nuclei. Interstitial fibrosis appears as thin collagen septa delimiting tumour lobules, as opposed to the broad fibrosis of Hodgkin-type lymphoma. Neoplastic cells exhibit a B-cell phenotype with expression of CD19, CD20 and CD22 [35]. In addition, the biological phenotype is marked by the expression of CD30, as well as in Hodgkin lymphoma and anaplastic lymphoma, where it is gaining ground as a therapeutic target. High cure rates can be achieved by using standard chemotherapy strategies (R-CHOP: rituximab/cyclophosphamide/doxorubicin/vincristine/prednisolone; R-VACOP-B: rituximab, etoposide/leucovorin/doxorubicin/cyclophosphamide/vincristine/prednisone/bleomycin), although for relapsing cases there is a convergence of opinion regarding the adoption of curative strategies limiting the need for mediastinal radiation [35, 36].

\section{Lymphoblastic lymphomas}

Lymphoblastic lymphomas are neoplasms originating from immature lymphoid cells committed to the B- or T-cell lineage [37]. Globally, these haematological malignancies account for $\sim 2 \%$ of all non-Hodgkin lymphomas [30]. Among lymphoblastic lymphomas, T-cell lineage tumours represent 90\% of cases, occurring especially in late childhood and young adults, with a male predilection. B-cell lineage lymphoblastic lymphoma has been reported in adults with median age of 40 years [30, 38, 39]. Mediastinal involvement is very frequently observed in lymphoblastic lymphoma, especially in tumours of T-cell lineage. It is characterised by a rapid growing mass located within the thymic lodge infiltrating adjacent structures and pleural effusion [40, 41]. Laboratory tests show leukocytosis with abnormal cells (blasts) and elevation of LDH. In the absence of abnormal cells on peripheral blood smears, biopsy can be considered to confirm the clinical suspicion of haematological malignancy and to precisely characterise the disease. The neoplastic tissue contains diffuse growth of sheets of small- to medium-sized lymphoid cells, with high proliferative activity. Immunophenotyping is fundamental for definitive diagnosis and lineage determination and may be performed on tissue specimens by immunohistochemistry or on peripheral blood by flow cytometry $[41,42]$. Despite the aggressive presentation, lymphoblastic lymphomas are generally curable diseases, when diagnosed and treated in a timely fashion [43, 44]. The use of novel intensive chemotherapy regimens has remarkably improved the prognosis in all age ranges, with disease-free survival rates up to $90 \%$ in children and up to $66 \%$ in adults $[45,46]$. At present there is no consensus about reliable prognostic factors in lymphoblastic lymphoma. Patients diagnosed with B-cell lineage disease seem to have better prognosis and high disease-free survival compared to those with tumours of the T-cell phenotype $[44,45]$. In addition, the elevation of LDH and central nervous system involvement appeared to be correlated to a poorer outcome and a more aggressive disease in patients diagnosed with T-type lymphoblastic lymphomas in different series [44-46]. In any case, the standard therapeutic approach for lymphoblastic lymphoma is based on intensive multidrug chemotherapy for induction, consolidation and maintenance [46, 47].

\section{Neuroendocrine tumours}

Primary mediastinal neuroendocrine tumours (NETs) are very uncommon, globally accounting for $\sim 5 \%$ of all thymic and mediastinal tumours. Most thoracic NETs arise in the anterior mediastinum, within the thymus, especially in middle-aged males. Although a proportion of cases do not present symptoms, clinical manifestations may be marked by local/metastatic tumour growth and endocrine-related symptoms. The current WHO classification of NETs identifies three groups of malignancy: low-grade (typical carcinoid), intermediate-grade (atypical carcinoid) and high-grade (large-cell neuroendocrine carcinoma and small-cell carcinoma). A proportion of carcinoids, especially at an advanced stage, may occur in the setting of multiple endocrine neoplasia type 1 .

On histopathological grounds, morphological traits of low- and high-grade NETs are well defined. Accurate evaluation of the tumour proliferation is crucial for the correct diagnosis; indeed, current accepted histopathological criteria of NET grading are based on mitotic count cut-off values. Moreover, although not formally validated in the current NET classification, the assessment of proliferative phenotype may also be supported by evaluating Ki67 tissue markers [48].

Finally, with regard to prognosis, patients with typical carcinoids have the best outcome, whereas atypical carcinoid diagnosis is related to slight worsening of prognosis. High-grade NETs are poor-prognosis neoplasms, with a median survival of 14 months for the small-cell carcinoma subtype [49].

\section{Paragangliomas}

Paragangliomas arising in the anterior or middle mediastinum are clinically and histologically similar to their cervical counterparts. In contrast, paragangliomas of the posterior mediastinum are similar to their 
retroperitoneal counterparts with possible catecholamine release [50]. It is important to differentiate paragangliomas (cytokeratin-negative) from thymic carcinoids (cytokeratin-positive), since familial paragangliomas may be associated with germline mutations such as succinate dehydrogenase gene mutations and patients may benefit from genetic testing [51].

\section{Soft tissue tumours}

Most soft tissue tumours arising elsewhere in the body have also been described in the mediastinum. In general, mediastinal soft tissue tumours are rare, with an estimated incidence of 2-6\% [52-54].

\section{Lipomatous tumours}

Lipomatous tumours may be located in any compartment. Among the adipocytic tumours, thymolipoma presents as a well-delineated mass arising from the anterior mediastinum; it is constituted of histologically mature fat incorporating thymic tissue. It more commonly occurs in young adults in their second or third decade, with an equal sex ratio [55]. Since these tumours grow slowly, symptoms such as shortness of breath and pain became apparent when the mass has reached several centimetres. Systemic symptoms such as myasthenia gravis, hyperthyroidism or anaemia may occur [56]. Surgical removal is the treatment of choice, leading to resolution of systemic disease. Malignant transformation does not occur and prognosis is excellent after surgery with no recurrence [57].

Liposarcoma is a malignant adipocytic tumour and represents the most common mediastinal soft-tissue malignant tumour. It mainly occurs in adult, even if scattered cases of mediastinal liposarcoma have been described in children [58]. When arising in the anterior mediastinum, it is named "thymoliposarcoma", thus emphasising an origin from the thymic tissue. Liposarcomas form large masses before generating symptoms and appear as large well-circumscribed masses [59]. All histological subtypes of liposarcoma may be found in mediastinum, with over-representation of the pleomorphic type. The treatment strategy is based on surgery [60].

\section{Solitary fibrous tumour}

Solitary fibrous tumour is a thoracic soft-tissue neoplasm exhibiting uncertain malignant potential. While most solitary fibrous tumours are of pleural origin, the mediastinal type may arise from mediastinal pleura from the epicardial layer [61]. They may be found in any mediastinal compartment and are typically diagnosed in adults without sex predilection. The mainstay of treatment is based on surgical resection [62].

\section{SMARCA4-deficient tumours}

In the mediastinum, SMARCA4-deficient tumours were recently described as a group of undifferentiated sarcomas [63]. These tumours occur in mediastinum, lung or both (figure 1). Patients are predominantly male and usually smokers. Prognosis is poor. Histologically, these tumours appear undifferentiated with sarcomatoid features. The loss of SMARCA4 protein expression results from mutations in the SMARCA4 gene [64]. Since SMARCA4 deficiency may occur in various tumours including lung carcinomas, the classification of SMARCA4-deficient undifferentiated tumours remains controversial. SMARCA4-deficient mediastinal sarcomas and SMARCA4-deficient pulmonary sarcomatoid carcinomas may belong to the same tumour spectrum with different degrees of differentiation [65].

\section{Cysts of the anterior mediastinum}

Congenital thymic cysts are not associated with myasthenia gravis and are usually discovered incidentally. Radiologically, they can simulate a thymoma. Multilocular thymic cysts are rare acquired inflammatory and often tumour-like lesions (figure 2). They are idiopathic or secondary to autoimmune diseases such as Sjögren syndrome [66] or HIV infection [67]. One case has been reported in association with IgG4-related disease [68]. Importantly, multilocular cysts may result from local inflammation related to neoplasms and especially lymphomas, seminoma or thymic epithelial tumours [69].

Pleuropericardial cysts, which are usually congenital lesions, are also called mesothelial cysts, serous cysts or coelomic cysts. Some pericardial cysts are in fact pericardial diverticula [69]. These cysts may occur anywhere in the mediastinum, but are mainly located in the cardiophrenic angle, especially on the right side. Most patients are asymptomatic or present with nonspecific chest pain or dyspnoea. Serious complications (compression, infection, haemorrhage or rupture) are exceptional. When histological confirmation is not necessary, percutaneous aspiration, possibly with ethanol sclerosis, may avoid or delay surgical resection [69]. 
a)
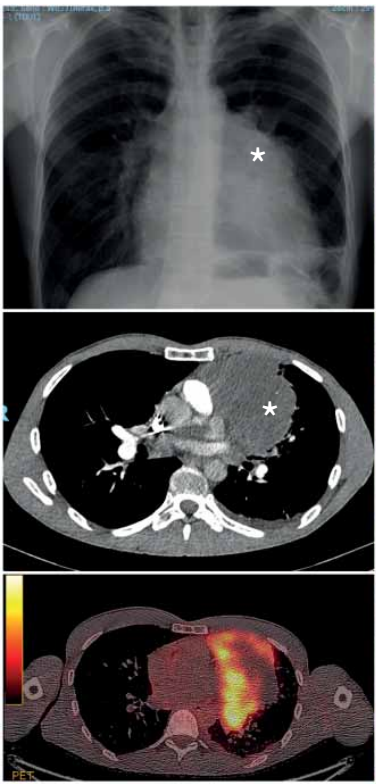

b)

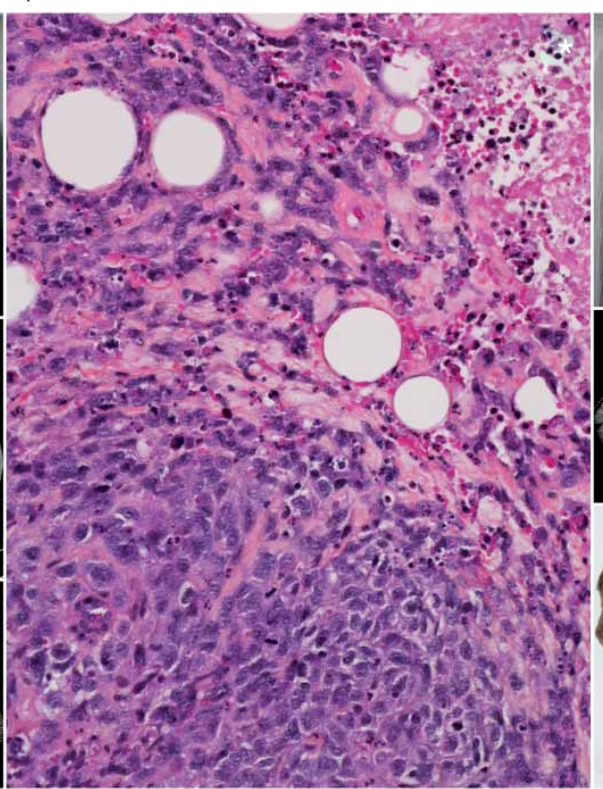

c)

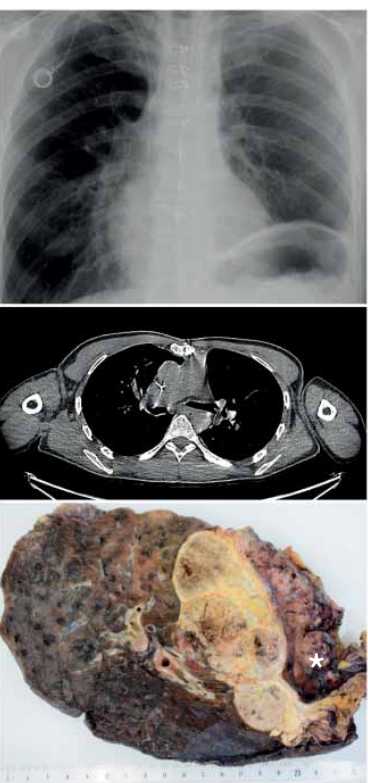

FIGURE 1 Radiological and pathological appearance of a SMARCA4-deficient tumour. a) Initial chest radiograph and computed tomographic (CT) scan showing a mediastino-pulmonary tumour ${ }^{*}$ ) with positivity on positron emission tomography; b) histology of the initial biopsy at medium magnification showing an undifferentiated tumour infiltrating fat, with mitoses and necrosis (*; top right); c) post-chemotherapy chest radiograph and CT scan showing tumour regression and macroscopic appearance of the surgical specimen showing a necrotic tumour infiltrating the left pulmonary upper lobe lung and pericardium $\left(^{*}\right)$.

Middle mediastinum

Diseases affecting the visceral (middle mediastinal) compartment comprise tracheal and oesophageal lesions, foregut cysts, lymphadenopathy and lesions of pericardial, heart and great vessels origin. This constitutes a main difference between ITMIG and JART classification of the mediastinal segment, as according to the latter, the heart and great vessels are not included in this compartment.

\section{Mediastinal lymphadenopathies}

Lymphadenopathy is one of the most frequent radiological findings identified within the middle mediastinum. This condition refers to the increase in size, the irregular shape and anomaly of the density of mediastinal nodes. The general accepted definition of mediastinal lymphadenopathy is that of a node with the short axis $>10 \mathrm{~mm}$ [70-72]. The assessment of nodal diseases requires CT scanning, which enables the evaluation of invasion of surrounding structures, the agglutination of several nodes and the alteration of the node consistency. The aetiology of thoracic lymphadenopathies may be inflammatory or neoplastic [70, 73]. With regard to benign aetiologies, infections such as tuberculosis and fungal infections (histoplasmosis) frequently result in mediastinal lymphoadenopathies. Moreover, sarcoidosis, drug reactions, heart failure, silicosis and Castleman disease represent additional disease groups leading to thoracic node enlargement.

\section{Benign diseases affecting thoracic nodes}

Granulomatous diseases (tuberculosis, sarcoidosis)

The initial focus of tuberculosis infection is represented by the lung tissue, where the middle and lower lobes are by far most affected, by reason of their ventilatory pattern. In the early stage, mycobacteria spread to regional lymph nodes, which progressively increase in size. As the disease progresses, the healing process may result in nodal tissue scarring and calcification. Lymphadenopathy is a central feature of mycobacterial infection, being observed in $40 \%$ of adults and up to $90 \%$ of paediatric cases of tuberculosis [74, 75]. On CT scans, features suggestive of tuberculosis are represented by nodes $>2 \mathrm{~cm}$, with hypodense centres and/or peripheral calcification. Biopsy samples can be obtained by endobronchial ultrasound-guided transbronchial needle aspiration (EBUS-TBNA), where cytological examination discloses classical pattern of acellular necrosis embedding inflammatory cells and granulomatous reaction [75]. 

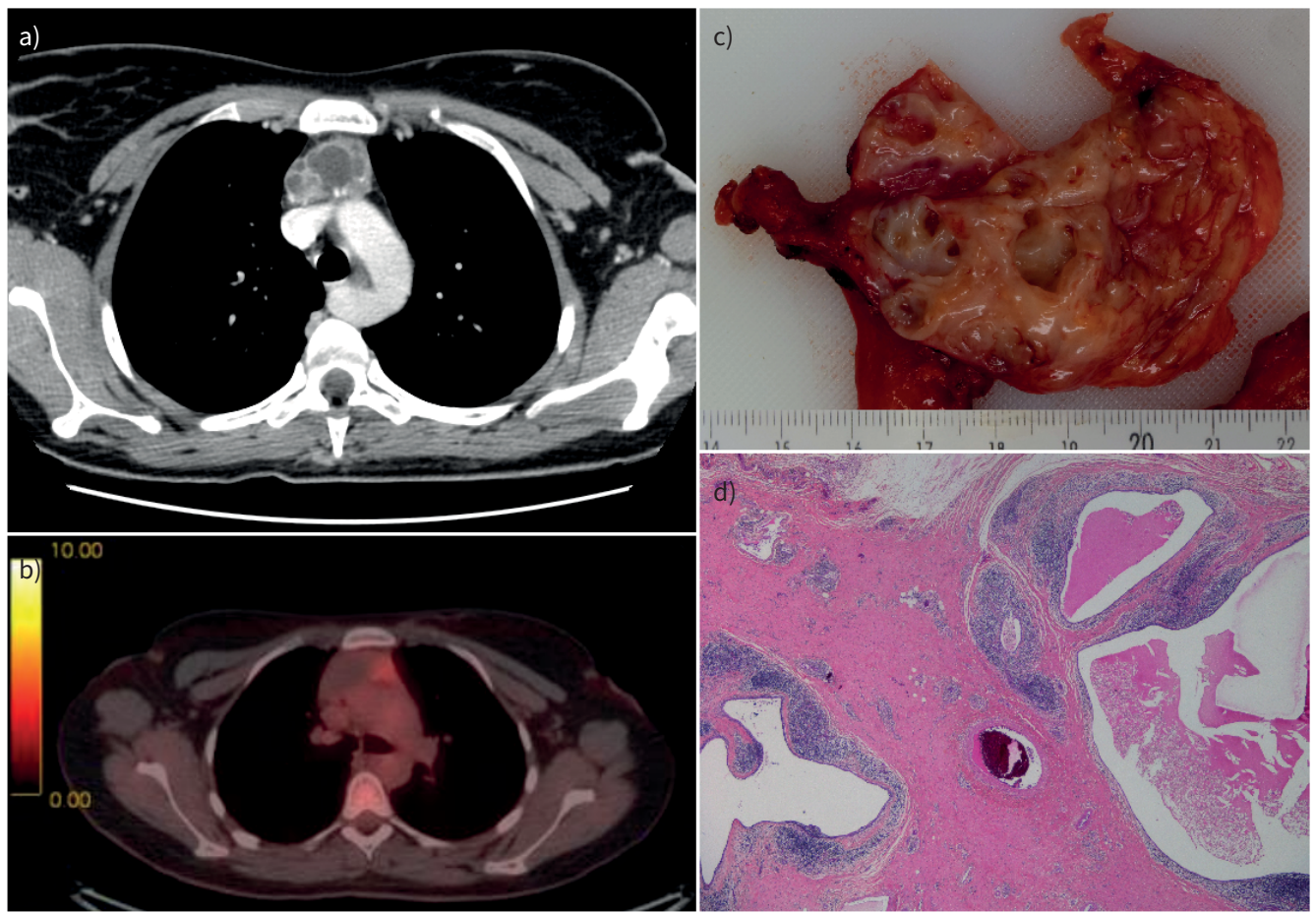

FIGURE 2 Radiological and pathological typical features of a multilocular thymic cyst. a) Computed tomographic (CT) scan showing the lesion in the anterior mediastinum; b) positron emission tomography showing a moderate hypermetabolism (standardised uptake value 3.7); c) gross appearance of the multilocular cystic lesion; d) histological appearance at low magnification showing several cavities with thick fibroinflammatory walls.

In case of high clinical suspicion of tuberculosis, or in presence of such cytological features at rapid on-site evaluation, part of the biopsy sample may be retained for bacteriological analysis. Additionally, a granulomatous reaction characterises sarcoidosis, a systemic disease primarily affecting the nodes and lungs [76]. Thoracic disease is marked by bilateral node enlargement in early-stage disease, while parenchymal infiltration is observed in the more advanced stages. The typical imaging pattern is characterised by bilateral hilar and paratracheal node enlargement. In chronic late-stage disease, calcifications may also be observed. Symmetrical involvement of mediastinal nodes with or without parenchymal lesions occurring in young patients is very supportive of a clinical diagnosis of sarcoidosis, which can be definitively confirmed on EBUS-TBNA specimens [77]. Granulomatous inflammation without necrosis is the major histopathological finding, eventually associated with fibrosis in case of long-lasting disease [77].

Pneumoconiosis (silicosis, berylliosis)

Inhalation of free silica dust while working (drilling, mining) may lead to silicosis, an occupational disease characterised by lung tissue lesions, potentially resulting in interstitial fibrosis [78, 79]. Mediastinal lymphadenopathies with extensive calcifications are commonly observed in this setting. Cytological samples are often paucicellular, by reason of the extensive nodal fibrosis, and are characterised by dense fibrous tissue, with abundant macrophages with storage of silica particles. Berylliosis is an occupational disease resulting from exposure to beryllium compounds [80]. It may result in acute pneumonia in case of intense exposure to beryllium or in chronic pulmonary condition. The latter form is more common, resulting in interstitial lung disease with bilateral lymphadenopathies in up to $25 \%$ of cases, involving the hilar and middle mediastinum nodes [80].

Chronic left heart failure, pulmonary embolism, idiopathic pulmonary fibrosis and COPD may also cause lymphadenopathies affecting thoracic subcarinal, paratracheal and hilar nodes. The pathogenesis of thoracic nodes enlargement depends on the aetiology, even if it is not entirely clear for all of these conditions [80-82]. 


\section{Castleman disease}

This condition is mainly unicentric, affecting a single lymph node or group of nodes within the chest or the abdomen [83-85]. It occurs in young patients and may be identified incidentally on chest radiographs, appearing as a solitary round homogeneous mediastinal or hilar lesion. Hypervascularity constitutes a major feature of Castleman disease, manifesting as an intense contrast enhancement [85, 86]. However, definitive diagnosis may require surgical biopsy to rule out lymphoma. Histologically, unicentric mediastinal Castleman disease is usually of hyaline vascular type with follicular hyperplasia, atrophic follicular centres, richly vascularised interfollicular hyperplasia and vessels with hyaline walls. Unicentric Castleman disease is benign and the treatment is based on surgical resection [86]. Conversely, multicentric Castleman disease, usually of histological plasma cell type, is an aggressive lymphoproliferative disorder associated with human herpesvirus 8 infection [86].

\section{Malignant diseases}

Malignancies affecting lymph nodes account for secondary localisation of thoracic or extrathoracic malignancies (metastasis of lung cancer, digestive cancer or gynaecological malignancies) or primary nodal lesions (haematological malignancies) [87-89].

\section{Metastasis of lung cancer}

Lungs contain a dense lymphatic network distributed within the pleura and the parenchyma: the pleural lymphatic network develops within the parietal and the visceral pleura and drains into the lung hilum where it connects with the parenchymal lymphatic supply [90-92]. The parenchymal lymphatics pass along the interlobular septa and the bronchoalveolar structures and before connecting with the pleural network and draining into the lobular, interlobular, hilar and mediastinal nodes [93-95]. However, the patterns of mediastinal node involvement depend on the site of origin of lung tumour. For instance, lesions from the right upper lobe predominantly drain into the right paratracheal and anterior mediastinal nodes. Middle and lower lobe lesions spread into the subcarinal and then into the paratracheal nodes. The left upper lobe drains within the subaortic and para-aortic lymph nodes, while the subcarinal nodes are the main draining goal from lesions of the left lower lobe [96, 97]. CT, combined with 18-2-fluoro-2-deoxy-D-glucose positron emission tomography $\left({ }^{18} \mathrm{FDG}-\mathrm{PET}\right)$ is very effective for the identification of mediastinal node alteration and allows planning of the most suitable form of biopsy (transbronchial/transoesophageal fine-needle aspiration or surgical approach) [87].

\section{Breast cancer}

The lymphatic spreading patterns of breast cancer course through three principal routes: the axillary, the transpectoral and the internal mammary patterns. However, if breast tumours block the normal lymphatic flow, collateral lymphatic pathways open, such as contralateral internal mammary and mediastinal lymphatics [98].

\section{Haematological diseases}

Thoracic involvement in haematological diseases occurs in most Hodgkin lymphoma and in up to $45 \%$ of non-Hodgkin lymphoma [99]. Anterior mediastinal and paratracheal lodges are the most common nodal regions involved in both Hodgkin and non-Hodgkin lymphomas. Distinction between Hodgkin and non-Hodgkin lymphoma requires histological examination of an adequate amount of tissue. For this reason, the surgical approach appears to be the most appropriate to assess diagnosis.

\section{Oesophageal carcinoma}

The oesophageal lymphatics form a dense network around the oesophagus. Thoracic node involvement is observed in tumours occurring in the upper or middle segment of the oesophagus, with paraoesophageal and paratracheal nodes being the most common regions of metastasis. Nodal metastatic disease is characterised by nodal enlargement $>1 \mathrm{~cm}$ in diameter [100].

On histological grounds, the two most common primary oesophageal malignancies are squamous cell carcinoma (SCC) and adenocarcinoma (ADC). While ADC occurs above all in the lower oesophagus, SCC (which is the most common oesophageal tumour worldwide) involves the middle or lower oesophagus equally. Therefore, the SCC subtype in particular enters differential diagnosis with other mediastinal malignancies, notably tracheal or bronchial malignancies. A radiological approach based on the centre method illustrated in the introduction may provide preliminary elements facilitating the differential diagnosis as well as bronchoscopic and endoscopic examination of mucosal tubular organs passing through the mediastinum. 
Tumours of the heart and great vessels

Tumours arising in the heart are very rare, with an estimated incidence of $0.02 \%$ [101-103]. The clinical presentation depends on tumour site and the degree of myocardial infiltration. For instance, tumours arising in the atria or centred on valves may cause blood flow obstruction, mimicking valve disease. Tumour infiltration deep into the myocardium may produce syndromes of hypertrophic and/or restrictive cardiomyopathy, or sudden death when neural trails are attained. Moreover, crossed embolism may occur, especially in the case of cardiac myxoma, which may undergo fragmentation because of its jelly-like structure. Treatment is based on surgical resection in combination with chemo/radiotherapy in cases of malignant disease. Benign tumours outnumber the malignant forms: $75 \%$ are benign neoplasms and 25\% are malignancies $[104,105]$.

Among benign tumours, myxoma is the most frequent type, accounting for up to $70 \%$ of primary heart tumours overall [106]. Most myxomas arise in the left atrium and rarely occur in the ventricles. Tumours are soft with gelatinous appearance, most often covered with thrombi. Most myxoma are sporadic and without recurrence after surgical removal. However, a limited number of cases arise in the setting of the Carney triad. Other benign cardiac tumours are represented by papillary fibroelastoma and rhabdomyoma. The first has a valvular origin and occurs in adults. The tumour structure is marked by multiple jelly-like papillae, reminiscent of a sea anemone. Surgical resection is curative [107]. Rhabdomyoma is the most common cardiac lesion at paediatric ages. It is located in the left ventricle myocardium or interventricular septum and it is rather considered to be an hamartomatous lesion; it has a tendency to spontaneous regression in half of patients.

Malignant neoplasms of the heart are rare, with an estimated prevalence between $0.001 \%$ and $0.28 \%$. These tumours are silent for a long time and symptoms appear in the advanced stages of disease, when the blood flow is hampered or cardiac valve function disrupted. Angiosarcoma, together with intimal sarcoma, is the most common histological type of cardiac sarcoma. It is most commonly found in the right heart, with predilection for the right atrium, and pericardial extension. Clinical presentation may be marked by acute cardiac failure and tamponade. Upon magnetic resonance imaging (MRI), angiosarcoma most often appears as lesions centred on the right atrium, with pericardial involvement and haemorrhagic effusion. Angiosarcoma is a very aggressive soft-tissue neoplasm with a striking tendency to metastasise, especially to the lungs. Treatment is not standardised and prognosis is constantly poor.

Fortunately, tumours of the great vessels are rare. With regard to mediastinal great vessels tumours intimal sarcoma represents the most common tumour of the pulmonary arteries. Symptoms are similar to pulmonary embolism. Although it may be difficult to distinguish sarcoma from thrombi, an imaging filling defect involving the trunk of the pulmonary artery and a significant enlargement of the vessel suggest a neoplastic lesion, rather than a thromboembolic condition. In addition, the extension beneath the vascular wall with impingement of neighbour organs may also orient clinicians towards an invasive proliferation. In addition, the enhancement of the lesion, disclosed at ${ }^{18}$ FDG-PET imaging, may contribute in differentiating pulmonary artery tumours from organised thrombus. The disease course is characterised by progressive local tumour growth, which may be associated with thrombosis leading to the formation of a superimposed blood clot and tumour emboli migration. Tumour may also spread to the pulmonary valve and into the right ventricle. The survival of patients without surgical treatment ranges between 1.5 and 5.5 months, with heart failure following vessel obstruction being the main cause of death. Chemotherapy and radiation are usually ineffective and wide surgical resection represents the unique means to slightly improve patients' survival.

\section{Cysts of the middle mediastinum}

Bronchogenic cysts usually develop in the middle mediastinum. The risk of complications (infection, rupture, fistulae into surrounding structures) and the risk of local recurrence following incomplete excision of complicated cyst, entails management with surgical resection.

\section{Posterior mediastinum}

The contents of the paravertebral compartment include the thoracic spine with the paravertebral soft tissue and ganglia; diseases arising from these structures represent the principal pathological alterations found within the posterior mediastinum.

\section{Neurogenic lesions}

Neurogenic tumours represent the most frequent cause of posterior mediastinal masses [108]. Most neurogenic tumours are benign and constitute a heterogeneous group of neoplasms, including tumours arising from peripheral nerves, those originating from sympathetic ganglia and those arising from 
parasympathetic ganglia [109]. Schwannoma, together with neurofibroma, are the most common neurogenic tumours occurring in the posterior mediastinum [110]. In particular, schwannomas are encapsulated neoplasm developing from the nerve sheath which progressively compresses the nerve fibre [110]. Clinically, most patients do not display symptoms except a small proportion who suffer from pain and/or paraesthesia because of compression of adjacent structures or spinal involvement. On CT imaging, schwannomas appear as sharp paraspinal masses sometimes attaining large sizes leading to erosion of vertebral bodies or ribs. Intraspinal extension should be assessed using MRI to plan a proper surgical approach [111]. Similar to schwannoma, neurofibroma is a benign nervous lesions arising from nerve sheaths, presenting as a lobulated but nonencapsulated paraspinal mass. It results from a disorganised proliferation of Schwann cells, fibroblasts and perineural cells. The plexiform variant forms a tumour diffusing along an entire nerve or plexus and it is always observed in the context of neurofibromatosis [112].

Malignant nerve sheath tumours are sarcomas of nervous origin, representing the malignant counterpart of benign tumours such as schwannoma and neurofibroma [113]. Malignant tumours of nerve sheath origin (MTNSO) may be sporadic or may occur in the setting of neurofibromatosis, where they develop on a pre-existing neurofibroma [114]. MTNSO forms a paraspinal mass with local invasion of adjacent mediastinal structures, clinically manifesting with focal neurological deficits and/or pain [115]. Surgical removal with wide tumour-free margins is the treatment of choice, when possible. However, in case of incomplete resection adjuvant radiotherapy is necessary [115]. Eventually, chemotherapy is useful in metastatic disease even if the overall prognosis remains poor, being negatively influenced by tumour size, and procedure of surgical removal and association of neurofibromatosis [116].

Neuroblastoma, ganglioneuroblastoma and ganglioneuroma are neoplasms arising from sympathetic ganglia [117]. Neuroblastoma is a typical malignant neoplasm of children, most often occurring before the age of 5 years [118]. Neuroblastoma forms a paraspinal mass, frequently invading adjacent structures and eroding bony tissues. Neuroblastoma (and ganglioneuroblastoma) cells may discharge catecholamine molecules causing hypertension and watery diarrhoea. These vasoactive metabolites may be detected in the
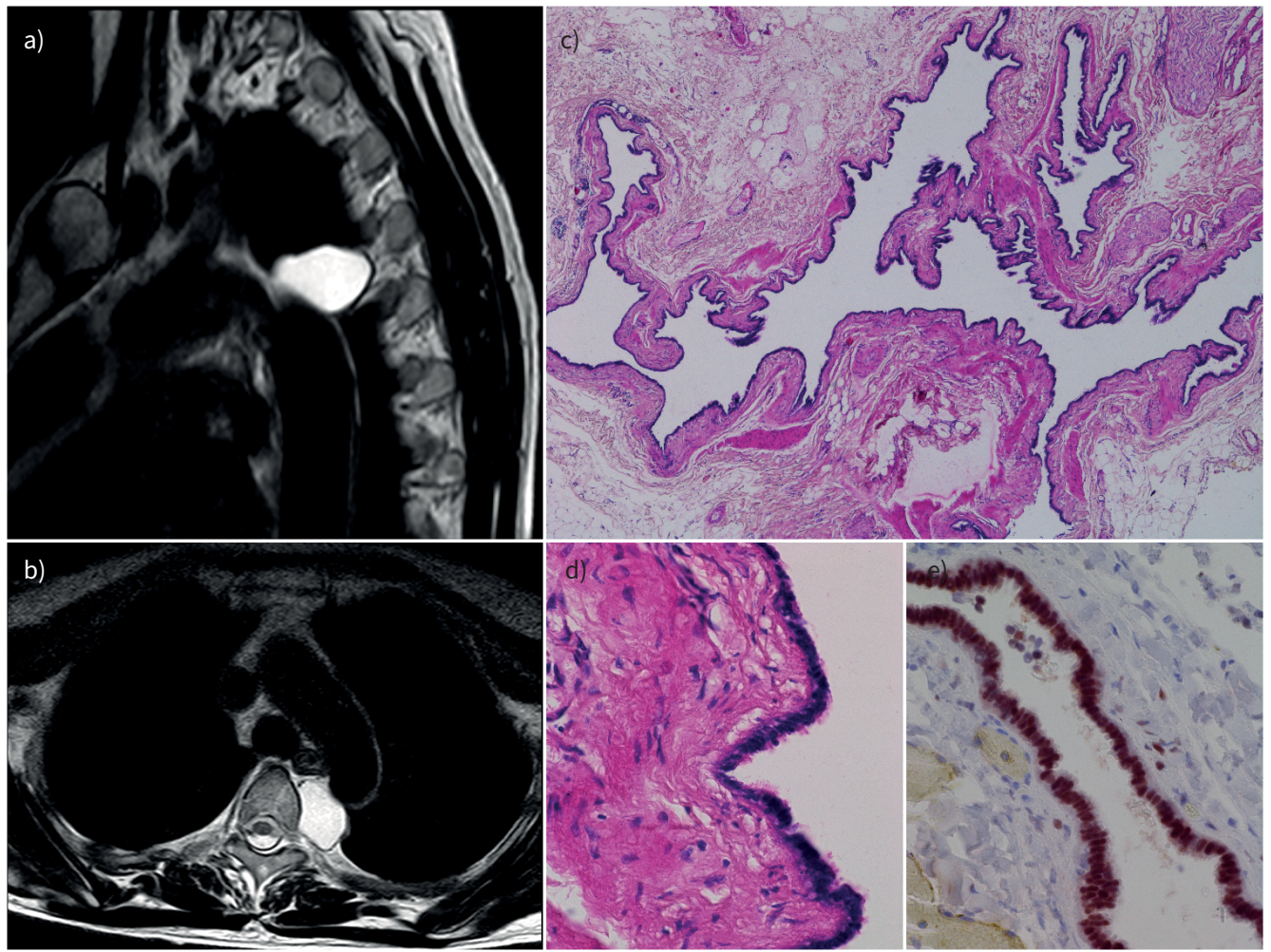

FIGURE 3 Radiological and histological typical features of Müllerian cysts of the mediastinum. a, b) Magnetic resonance imaging showing a paravertebral cystic lesion; c) histological features at low magnification showing a cystic lesion resembling a fallopian tube; d) histological appearance of the ciliated epithelium of the cyst at high magnification; e) immunohistochemistry showing strong oestrogen receptor nuclear expression. 
urine of patients and are useful in disease monitoring. The treatment modality depends on the disease stage; indeed, advanced diseases require chemotherapy and radiotherapy, while surgery is curative in localised disease. Negative prognostic factors include tumour stage, age at diagnosis, poorly differentiated histology and extrathoracic primary site [118].

As opposed to neuroblastoma and ganglioneuroblastoma, ganglioneuroma is a neoplasm composed of mature ganglion cells. These tumours occur in children and young adults and are definitively treated by simple surgical excision.

\section{Cartilage tumours}

Chondrosarcomas are cartilage-forming tumours most often affecting the pelvis and the extremities. Chest location involves most commonly the ribs and the sternum, while the costotransverse junction is affected on rare occasions. Chondrosarcomas typically occur in adults, and when located posteriorly in the chest, they may invade spinal nerves leading to neurological symptoms and pain. Surgery is the mainstay of treatment and prognosis is influenced by tumour size, grade and location [119].

\section{Cysts of the posterior mediastinum}

Müllerian cysts are rare mediastinal paravertebral lesions (figure 3) that have been reported only recently [120]. These cysts only occur in females and radiologically can mimic a neural tumour. Histologically, Müllerian cysts look like fallopian tubes. They are lined by ciliated epithelium and have a muscular wall [120]. Unlike bronchogenic cysts, Müllerian cysts do not contain mucus, cartilage, seromucous glands and pseudostratified epithelium with goblet cells. In doubtful cases, expression of oestrogens and progesterone receptors can confirm the diagnosis. Since Müllerian cysts are not reported to lead to any serious complications, a conservative management could be considered if the diagnosis can be achieved by radiological imaging [4].

\section{Conclusion}

In this review we illustrate the heterogeneity of mediastinal lesions, pointing out several issues encountered in the diagnostic proceedings. The integration of patient information such as age, sex with clinical presentation and imaging appears fundamental to assess a presumptive diagnosis with a good level of certainty. The present compendium of mediastinal lesions is based on the long-lasting anatomoclinical experience of our tertiary referring institution. New diagnostic tools have become widely available in recent decades, especially PET and EBUS needle biopsy. Thoracic surgery has also become less aggressive with the widespread use of video-assisted thoracoscopy. Pathologists have recently described rare new entities occurring in the mediastinum, such as SMARCA4-deficient tumours. In the wake of emerging personalised/targeted treatment strategies, such as tyrosine kinase inhibitors or immunotherapy, mediastinal tumours should not become a "forgotten entity", since these neoplasms frequently mirror a pot-pourri of well-known tumour entities of other organs/sites.

Provenance: Commissioned article, peer reviewed.

Previous articles in this series: No. 1: Eichhorn F, Winter H. How to handle oligometastatic disease in nonsmall cell lung cancer. Eur Respir Rev 30: 2021; 200234. No. 2: Asciak R, George V, Rahman NM. Update on biology and management of mesothelioma. Eur Respir Rev 30: 2021; 200226. No. 3: Finazzi T, Schneiders FL, Senan S. Developments in radiation techniques for thoracic malignancies. Eur Respir Rev 30: 2021; 200224. No. 4: Huber RM, Kauffmann-Guerrero D, Hoffmann $\mathrm{H}$, et al. New developments in locally advanced nonsmall cell lung cancer. Eur Respir Rev 30: 2021; 200227. No. 5: Rittmeyer A, Schiwitza A, Sahovic L, et al. Update on recent key publications in lung oncology: picking up speed. Eur Respir Rev 30: 2021; 200300. No. 6: Abdayem P, Planchard D. Update on molecular pathology and role of liquid biopsy in nonsmall cell lung cancer. Eur Respir Rev 30: 2021; 200294. No. 7: Lam S, Tammemagi M. Contemporary issues in the implementation of lung cancer screening. Eur Respir Rev 30: 2021; 200288.

Conflict of interest: M-R. Ghigna has nothing to disclose. V. Thomas de Montpreville has nothing to disclose.

\section{References}

1 Fujimoto K, Hara M, Tomiyama N, et al. Proposal for a new mediastinal compartment classification of transverse plane images according to the Japanese Association for Research on the Thymus (JART) General Rules for the Study of Mediastinal Tumors. Oncol Rep 2014; 31: 565-572.

2 Carter BW, Tomiyama N, Bhora FY, et al. A modern definition of mediastinal compartments. J Thorac Oncol 2014; 9: S97-S101. 
3

Whooley BP, Urschel JD, Antkowiak JG, et al. Primary tumors of the mediastinum. J Surg Oncol 1999; 70: 95-99.

Davis RD, Oldham HN, Sabiston DC. Primary cysts and neoplasms of the mediastinum: recent changes in clinical presentation, methods of diagnosis, management, and results. Ann Thorac Surg 1987; 44: 229-237.

Travis WD, Brambilla E, Burke AP, et al. Introduction to the 2015 World Health Organization classification of tumors of the lung, pleura, thymus, and heart. J Thorac Oncol 2015; 10: 1240-1242.

Ruffini E, Van Raemdonck D, Detterbeck F, et al. Management of thymic tumors: a survey of current practice among members of the European Society of Thoracic Surgeons. J Thorac Oncol 2011; 6: 614-623.

Inaoka T, Takahashi K, Mineta M, et al. Thymic hyperplasia and thymus gland tumors: differentiation with chemical shift MR imaging. Radiology 2007; 243: 869-876.

Chen P, Wang Y-P, Mou D-L, et al. Pathological findings in myasthenia gravis patients with thymic hyperplasia and thymoma. Pathol Oncol Res 2018; 24: 67-74.

Basse C, Girard N.Thymic tumours and their special features. Eur Respir Rev 2022; in press [https://doi.org/ 10/1193/16000617.0394-2020].

Bokemeyer C, Nichols CR, Droz J-P, et al. Extragonadal germ cell tumors of the mediastinum and retroperitoneum: results from an international analysis. J Clin Oncol 2002; 20: 1864-1873.

Lemarié $\mathrm{E}$, Assouline PS, Diot $\mathrm{P}$, et al. Primary mediastinal germ cell tumors. Results of a French retrospective study. Chest 1992; 102: 1477-1483.

Kao C-S, Bangs CD, Aldrete G, et al. A clinicopathologic and molecular analysis of 34 mediastinal germ cell tumors suggesting different modes of teratoma development. Am J Surg Pathol 2018; 42: 1662-1673.

Alkan M, Karnak I, Ciftci AO, et al. Thymic teratoma or thymic remnant attached to mediastinal teratoma? The cellular origin of mediastinal teratomas revisited. Eur J Pediatr Surg 2004; 14: 117-119.

Lewis BD, Hurt RD, Payne WS, et al. Benign teratomas of the mediastinum. J Thorac Cardiovasc Surg 1983; 86: 727-731.

Friedman SJ, Belbel RL, Martin NJ. Extragonadal mediastinal seminoma. Mil Med 1988; 153: 32-34.

Weissferdt A, Rodriguez-Canales J, Liu $\mathrm{H}$, et al. Primary mediastinal seminomas: a comprehensive immunohistochemical study with a focus on novel markers. Hum Pathol 2015; 46: 376-383.

Economou JS, Trump DL, Holmes EC, et al. Management of primary germ cell tumors of the mediastinum. J Thorac Cardiovasc Surg 1982; 83: 643-649.

Wright CD, Kesler KA, Nichols CR, et al. Primary mediastinal nonseminomatous germ cell tumors. Results of a multimodality approach. J Thorac Cardiovasc Surg 1990; 99: 210-217.

Grabski DF, Pappo AS, Krasin MJ, et al. Long-term outcomes of pediatric and adolescent mediastinal germ cell tumors: a single pediatric oncology institutional experience. Pediatr Surg Int 2017; 33: 235-244.

Fizazi K, Culine S, Droz JP, et al. Tumeurs germinales non séminomateuses médiastinales primitives: de la clinique à la biologie. [Primary mediastinal non-seminomatous germ-cell tumors: from clinics to biology]. Bull Cancer 1997; 84: 313-327.

Lichtenstein AK, Levine A, Taylor CR, et al. Primary mediastinal lymphoma in adults. Am J Med 1980; 68: 509-514.

Raemaekers J, Kluin-Nelemans H, Teodorovic I, et al. The achievements of the EORTC Lymphoma Group. European Organisation for Research and Treatment of Cancer. Eur J Cancer 2002; 38: Suppl. 4, S107-S113.

Johnson PWM. IV. Masses in the mediastinum: primary mediastinal lymphoma and intermediate types. Hematol Oncol 2015; 33: Suppl. 1, 29-32.

Sharafkhaneh A, Baaklini W, Gorin AB, et al. Yield of transbronchial needle aspiration in diagnosis of mediastinal lesions. Chest 2003; 124: 2131-2135.

Piña-Oviedo S, Moran CA. Primary mediastinal nodal and extranodal non-Hodgkin lymphomas: current concepts, historical evolution, and useful diagnostic approach: part 1. Adv Anat Pathol 2019; 26: 346-370.

Assaad MW, Pantanowitz L, Otis CN. Diagnostic accuracy of image-guided percutaneous fine needle aspiration biopsy of the mediastinum. Diagn Cytopathol 2007; 35: 705-709.

Elia S, Cecere C, Giampaglia F, et al. Mediastinoscopy vs. anterior mediastinotomy in the diagnosis of mediastinal lymphoma: a randomized trial. Eur J Cardiothorac Surg 1992; 6: 361-365.

McCarten KM, Nadel HR, Shulkin BL, et al. Imaging for diagnosis, staging and response assessment of Hodgkin lymphoma and non-Hodgkin lymphoma. Pediatr Radiol 2019; 49: 1545-1564.

Gobbi PG, Ferreri AJM, Ponzoni M, et al. Hodgkin lymphoma. Crit Rev Oncol Hematol 2013; 85: 216-237.

Sandlund JT. Non-Hodgkin lymphoma in children. Curr Hematol Malig Rep 2015; 10: 237-243.

Thacker N, Bakhshi S, Chinnaswamy G, et al. Management of non-Hodgkin lymphoma: ICMR consensus document. Indian J Pediatr 2017; 84: 382-392.

Pfau D, Smith DA, Beck R, et al. Primary mediastinal large B-cell lymphoma: a review for radiologists. AJR Am J Roentgenol 2019; 213: W194-W210.

Mottok A, Wright G, Rosenwald A, et al. Molecular classification of primary mediastinal large B-cell lymphoma using routinely available tissue specimens. Blood 2018; 132: 2401-2405. 
Messmer M, Tsai H-L, Varadhan R, et al. R-CHOP without radiation in frontline management of primary mediastinal B-cell lymphoma. Leuk Lymphoma 2019; 60: 1261-1265.

Martelli M, Ferreri A, Di Rocco A, et al. Primary mediastinal large B-cell lymphoma. Crit Rev Oncol Hematol 2017; 113: 318-327.

Hochberg J, El-Mallawany NK, Abla O. Adolescent and young adult non-Hodgkin lymphoma. Br J Haematol 2016; 173: 637-650.

Schaefer NG, Hany TF, Taverna C, et al. Non-Hodgkin lymphoma and Hodgkin disease: coregistered FDG PET and CT at staging and restaging - do we need contrast-enhanced CT? Radiology 2004; 232: 823-829. Hsi ED. Pathology of primary cutaneous B-cell lymphomas: diagnosis and classification. Clin Lymphoma 2004; 5: 89-97.

Magrath IT. Management of high-grade lymphomas. Oncology 1998; 12: 40-48. Das DK. Serous effusions in malignant lymphomas: a review. Diagn Cytopathol 2006; 34: 335-347. Patel T, Patel P, Mehta S, et al. The value of cytology in diagnosis of serous effusions in malignant lymphomas: an experience of a tertiary care center. Diagn Cytopathol 2019; 47: 776-782.

Ritz J, Nadler LM, Bhan AK, et al. Expression of common acute lymphoblastic leukemia antigen (CALLA) by lymphomas of B-cell and T-cell lineage. Blood 1981; 58: 648-652.

Brugières L, Minard V, Patte C. Lymphomes de l'enfant et de l'adolescent. [Lymphomas in children and adolescents]. Rev Prat 2012; 62: 453-458.

Pehlivan KC, Duncan BB, Lee DW. CAR-T cell therapy for acute lymphoblastic leukemia: transforming the treatment of relapsed and refractory disease. Curr Hematol Malig Rep 2018; 13: 396-406.

Kansagra A, Dahiya S, Litzow M. Continuing challenges and current issues in acute lymphoblastic leukemia. Leuk Lymphoma 2018; 59: 526-541.

Cairo MS, Beishuizen A. Childhood, adolescent and young adult non-Hodgkin lymphoma: current perspectives. Br J Haematol 2019; 185: 1021-1042.

Rafei H, Kantarjian HM, Jabbour EJ. Recent advances in the treatment of acute lymphoblastic leukemia. Leuk Lymphoma 2019; 60: 2606-2621.

Brcic L, Heidinger M, Popper H. Neuroendokrine Neoplasien des Mediastinums. [Neuroendocrine neoplasms of the mediastinum]. Pathologe 2016; 37: 434-440.

Sher T, Dy GK, Adjei AA. Small cell lung cancer. Mayo Clin Proc 2008; 83: 355-367.

Ocazionez D, Shroff GS, Vargas D, et al. Imaging of intrathoracic paragangliomas. Semin Ultrasound CT MR 2017; 38: 584-593.

Dermawan JK, Mukhopadhyay S, Shah AA. Frequency and extent of cytokeratin expression in paraganglioma: an immunohistochemical study of 60 cases from 5 anatomic sites and review of the literature. Hum Pathol 2019; 93: 16-22.

Dubashi B, Cyriac S, Tenali SG. Clinicopathological analysis and outcome of primary mediastinal malignancies - a report of 91 cases from a single institute. Ann Thorac Med 2009; 4: 140-142.

Pachter MR, Lattes R. Mesenchymal tumors of the mediastinum. I. Tumors of fibrous tissue, adipose tissue, smooth muscle, and striated muscle. Cancer 1963; 16: 74-94.

Wychulis AR, Payne WS, Clagett OT, et al. Surgical treatment of mediastinal tumors: a 40 year experience. J Thorac Cardiovasc Surg 1971; 62: 379-392.

Ogino S, Franks TJ, Deubner H, et al. Thymohemangiolipoma, a rare histologic variant of thymolipoma: a case report and review of the literature. Ann Diagn Pathol 2000; 4: 236-239.

Pan $\mathrm{CH}$, Chiang $\mathrm{CY}$, Chen SS. Thymolipoma in patients with myasthenia gravis: report of two cases and review. Acta Neurol Scand 1988; 78: 16-21.

Taniguchi T, Usami N, Oohata N, et al. [Thymolipoma associated with myasthenia gravis]. Kyobu Geka 2009; 62: 1154-1157.

Sbrana F, Ugolini C, Taddei C, et al. Mediastinal dedifferentiated liposarcoma. Acta Cardiol 2017; 72 : 499-500.

Krishnasamy S, Krishna Nair A, Hashim SA, et al. Mediastinal liposarcoma: a rare visceral mediastinal tumour. Interact Cardiovasc Thorac Surg 2019; 29: 976-977.

Doğan R, Ayrancioğlu K, Aksu O. Primary mediastinal liposarcoma. A report of a case and review of the literature. Eur J Cardiothorac Surg 1989; 3: 367-370.

Witkin GB, Rosai J. Solitary fibrous tumor of the mediastinum. A report of 14 cases. Am J Surg Pathol 1989; 13: $547-557$.

Suehisa H, Yamashita M, Komori E, et al. Solitary fibrous tumor of the mediastinum. Gen Thorac Cardiovasc Surg 2010; 58: 205-208.

Perret R, Chalabreysse L, Watson S, et al. SMARCA4-deficient thoracic sarcomas: clinicopathologic study of 30 cases with an emphasis on their nosology and differential diagnoses. Am J Surg Pathol 2019; 43: 455-465.

4 Chetty R, Serra S. SMARCA family of genes. J Clin Pathol 2020; 73: 257-260. 
Rekhtman N, Montecalvo J, Chang JC, et al. SMARCA4-deficient thoracic sarcomatoid tumors represent primarily smoking-related undifferentiated carcinomas rather than primary thoracic sarcomas. $J$ Thorac Oncol 2020; 15: 231-247.

Nam JG, Goo JM, Park CM, et al. Age- and gender-specific disease distribution and the diagnostic accuracy of CT for resected anterior mediastinal lesions. Thorac Cancer 2019; 10: 1378-1387.

Shi X, Nasseri F, Berger DM, et al. Large multilocular thymic cyst: a rare finding in an HIV positive adult female. J Clin Imaging Sci 2012; 2: 55.

Oda R, Okuda K, Murase T, et al. Thymic inflammatory pseudotumor with multilocular thymic cyst caused by immunoglobulin G4-related disease. Thorac Cancer 2019; 10: 116-119.

Saridakis N, Koumantzia C, Libard S, et al. Intramedullary holocord mature teratoma in an adult - case report and review of the literature. Clin Neurol Neurosurg 2020; 195: 105925.

Henschke $\mathrm{Cl}$, Lee I-J, Wu N, et al. CT screening for lung cancer: prevalence and incidence of mediastinal masses. Radiology 2006; 239: 586-590.

Yasufuku K, Nakajima T, Fujiwara T, et al. Utility of endobronchial ultrasound-guided transbronchial needle aspiration in the diagnosis of mediastinal masses of unknown etiology. Ann Thorac Surg 2011; 91: 831-836.

Ustabasioglu FE, Samanci C, Alis D, et al. Apparent diffusion coefficient measurement in mediastinal lymphadenopathies: differentiation between benign and malignant lesions. J Clin Imaging Sci 2017; 7: 12.

Nin CS, de Souza VVS, do Amaral RH, et al. Thoracic lymphadenopathy in benign diseases: a state of the art review. Respir Med 2016; 112: 10-17.

Carmona EM, Kalra S, Ryu JH. Pulmonary sarcoidosis: diagnosis and treatment. Mayo Clin Proc 2016; 91: 946-954.

Kienzl-Palma D, Prosch H. Thorakale Manifestation der Tuberkulose. [Thoracic manifestation of tuberculosis]. Radiologe 2016; 56: 866-873.

Wessendorf TE, Bonella F, Costabel U. Diagnosis of sarcoidosis. Clin Rev Allergy Immunol 2015; 49: 54-62.

Patterson KC, Chen ES. The pathogenesis of pulmonary sarcoidosis and implications for treatment. Chest 2018; 153: 1432-1442.

Shi P, Xing X, Xi S, et al. Trends in global, regional and national incidence of pneumoconiosis caused by different aetiologies: an analysis from the Global Burden of Disease Study 2017. Occup Environ Med 2020; 77: 407-414.

Honma K, Abraham JL, Chiyotani K, et al. Proposed criteria for mixed-dust pneumoconiosis: definition, descriptions, and guidelines for pathologic diagnosis and clinical correlation. Hum Pathol 2004; 35: 1515-1523.

Fujimura N. Pathology and pathophysiology of pneumoconiosis. Curr Opin Pulm Med 2000; 6: 140-144.

Godbole RH, Saggar R, Kamangar N. Pulmonary tumor thrombotic microangiopathy: a systematic review. Pulm Circ 2019; 9: 2045894019851000.

Klok FA, van der Bijl N, de Roos A, et al. Is pulmonary embolism associated with reactive mediastinal and hilar lymphadenopathy? Thromb Res 2010; 125: 557-558.

Wu D, Lim MS, Jaffe ES. Pathology of Castleman disease. Hematol Oncol Clin North Am 2018; 32: 37-52.

van Rhee F, Munshi NC. Castleman disease. Hematol Oncol Clin North Am 2018; 32: xiii-xiv.

Wong RSM. Unicentric Castleman disease. Hematol Oncol Clin North Am 2018; 32: 65-73.

Abramson JS. Diagnosis and management of Castleman disease. J Natl Compr Canc Netw 2019; 17: 1417-1419.

Dhooria S, Mehta RM, Madan K, et al. A multicenter study on the utility of EBUS-TBNA and EUS-B-FNA in the diagnosis of mediastinal lymphoma. J Bronchology Interv Pulmonol 2019; 26: 199-209.

Cahoon AR, Smith BD, Yang WT. Internal thoracic lymphadenopathy in breast cancer. Radiographics 2017; 37: 1024-1036.

Korrungruang P, Boonsarngsuk V. Diagnostic value of endobronchial ultrasound elastography for the differentiation of benign and malignant intrathoracic lymph nodes. Respirology 2017; 22: 972-977.

Riquet M, Hidden G, Debesse B. Direct lymphatic drainage of lung segments to the mediastinal nodes. An anatomic study on 260 adults. J Thorac Cardiovasc Surg 1989; 97: 623-632.

Qi L-P, Yan W-P, Chen K-N, et al. Discrimination of malignant versus benign mediastinal lymph nodes using diffusion MRI with an IVIM model. Eur Radiol 2018; 28: 1301-1309.

2 Herrera Lara S, Fernández-Fabrellas E, Juan Samper G, et al. Predicting malignant and paramalignant pleural effusions by combining clinical, radiological and pleural fluid analytical parameters. Lung 2017; 195: 653-660.

Sarrazin R, Dyon JF. La médiastinoscopie. [Mediastinoscopy]. Rev Mal Respir 1992; 9: 99-110.

Eickhoff L, Golpon H, Zardo P, et al. Endobronchial ultrasound in suspected non-malignant mediastinal lymphadenopathy. Pneumologie 2018; 72: 559-567.

Kyburz P, Raeder EA, Burckhardt D. Klinische aspekte der infectiösen endokarditis. [Clinical aspects of infectious endocarditis]. Schweiz Rundsch Med Prax 1978; 67: 231-236. 

tracheobronchial lymph nodes junction: applications in lung cancer. Clin Anat 2016; 29: 955-962. human lungs. Ann Anat 2009; 191: 568-574.

98 Borgstein PJ, Meijer S, Pijpers RJ, et al. Functional lymphatic anatomy for sentinel node biopsy in breast cancer: echoes from the past and the periareolar blue method. Ann Surg 2000; 232: 81-89.

99 Bligh MP, Borgaonkar JN, Burrell SC, et al. Spectrum of CT findings in thoracic extranodal non-Hodgkin lymphoma. Radiographics 2017; 37: 439-461.

100 Riquet M, Saab M, Le Pimpec Barthes F, et al. Lymphatic drainage of the esophagus in the adult. Surg Radiol Anat 1993; 15: 209-211.

101 Fatima J, Duncan AA, Maleszewski JJ, et al. Primary angiosarcoma of the aorta, great vessels, and the heart. J Vasc Surg 2013; 57: 756-764.

102 Amano J, Nakayama J, Yoshimura Y, et al. Clinical classification of cardiovascular tumors and tumor-like lesions, and its incidences. Gen Thorac Cardiovasc Surg 2013; 61: 435-447.

103 Bendel EC, Maleszewski JJ, Araoz PA. Imaging sarcomas of the great vessels and heart. Semin Ultrasound CT MR 2011; 32: 377-404.

104 Poterucha TJ, Kochav J, O'Connor DS, et al. Cardiac tumors: clinical presentation, diagnosis, and management. Curr Treat Options Oncol 2019; 20: 66.

105 Linfeng Q, Xingjie X, Henry D, et al. Cardiac angiosarcoma: a case report and review of current treatment. Medicine 2019; 98: e18193.

106 Jain S, Maleszewski JJ, Stephenson CR, et al. Current diagnosis and management of cardiac myxomas. Expert Rev Cardiovasc Ther 2015; 13: 369-375.

107 Yong MS, Smail H, Saxena P. Management of incidental papillary fibroelastoma: an update. Int J Cardiol 2016; 215: 338-339.

108 Strollo DC, Rosado-de-Christenson ML, Jett JR. Primary mediastinal tumors: part II. Tumors of the middle and posterior mediastinum. Chest 1997; 112: 1344-1357.

109 Bicakcioglu P, Demirag F, Yazicioglu A, et al. Intrathoracic neurogenic tumors. Thorac Cardiovasc Surg 2014; 62: 147-152.

110 Pavlus JD, Carter BW, Tolley MD, et al. Imaging of thoracic neurogenic tumors. AJR Am J Roentgenol 2016; 207: 552-561.

111 Ratbi MB, Oueriachi El F, Arsalane A, et al. Surgery of benign neurogenic tumors in adults: single institution experience. Pan Afr Med J 2014; 19: 288.

112 Bakshi SS. Plexiform neurofibroma. Cleve Clin J Med 2016; 83: 792.

113 Durbin AD, Ki DH, He S, et al. Malignant peripheral nerve sheath tumors. Adv Exp Med Biol 2016; 916: 495-530.

114 Martinez AP, Fritchie KJ. Update on peripheral nerve sheath tumors. Surg Pathol Clin 2019; 12: 1-19.

115 Khu KJ, Midha R. Malignant peripheral nerve sheath tumors. World Neurosurg 2016; 94: 566-567.

116 Miettinen MM, Antonescu CR, Fletcher CDM, et al. Histopathologic evaluation of atypical neurofibromatous tumors and their transformation into malignant peripheral nerve sheath tumor in patients with neurofibromatosis 1 - a consensus overview. Hum Pathol 2017; 67: 1-10.

117 Oldridge DA, Truong B, Russ D, et al. Differences in genomic profiles and outcomes between thoracic and adrenal neuroblastoma. J Natl Cancer Inst 2019; 111: 1192-1201.

118 Murphy JM, La Quaglia MP. Advances in the surgical treatment of neuroblastoma: a review. Eur J Pediatr Surg 2014; 24: 450-456.

119 Keskin F, Kalkan H, Kaciran BK, et al. Primary tumor of thoracic vertebra: chondrosarcoma. Spine J 2016; 16: e33-e34.

120 Fukada Y, Endo Y, Nakanowatari H, et al. Bronchogenic cyst of the interatrial septum. Fukushima J Med Sci 2020; 66: 41-43. 